\title{
我国国家公园自然资源管理探讨
}

\author{
李款 (1) $1,2,3,4^{*}$, 李发祥 ${ }^{1}$
}

1. 三江源国家公园管理局，西宁 810000；2. 中国科学院西北生态环境资源研究院，兰州 730000; 3. 中国科学院大学，北京 100049 ; 4. 青海省治多县索加乡人民政府, 青海玉树 815000

摘要：2017年，我国在部分国家公园体制试点区启动了国有自然资源资产管理体制试点，旨在为国家公园等重要生态空间自 然资源管理积累经验。2021年10月12日，习近平主席宣布设立第一批国家公园。因此，探讨国家公园的自然资源管理具有重 要的现实意义, 可为未来资源环境领域的管理提供参考。本文对国家公园自然资源管理体制试点开展了调研。研究发现, 国 家公园自然资源管理工作在机构设置、地方立法、权责划分等方面取得进展。我国已建立中央垂直管理、中央和地方共同管 理、地方管理等国家公园自然资源管理体制, 各省级立法机构共出台了5部国家公园地方性法规，为国家公园自然资源管理提 供了法律依据。此外，南山国家公园管理局和武夷山国家公园管理局印发了权责清单，为国家公园自然资源管理职责划分做 了有益探索。但还存在一些问题, 如国家公园自然资源管理体制映射关系复杂、自然资源权属需进一步厘清、顶层设计需进 一步加快等。为此, 本文从构建集中统一管理体制、完善国家公园法治体系、厘清自然资源权属关系、有序开展社区人口转 移等方面提出了建议, 以期为国家公园自然资源管理提供参考。

关键词：国家公园；自然资源管理；管理体制；土地权属

李款，李发祥 (2022) 我国国家公园自然资源管理探讨. 生物多样性, 30, 21179. doi: 10.17520/biods.2021179.

Li K, Li FX (2022) Natural resource management of China's national parks. Biodiversity Science, 30, 21179. doi: 10.17520/biods.2021179.

\section{Natural resource management of China's national parks}

\author{
Kuan Li ${ }^{\left(D 1,2,3,4^{*}\right.}$, Faxiang $\mathrm{Li}^{1}$ \\ 1 Three-River-Source National Park Service, Xining 810007 \\ 2 Northwest Institute of Eco-Environment and Resources, Chinese Academy of Sciences, Lanzhou 730000 \\ 3 University of Chinese Academy of Sciences, Beijing 100049 \\ 4 People's Government of Suojia Town, Zhiduo County, Qinghai Province, Yushu, Qinghai 815000
}

\section{ABSTRACT}

Background \& Aims: In 2017, China launched a pilot state-owned natural resource asset management system in some pilot areas of the national park system, aiming to accumulate experience in the management of important ecological space natural resources such as national parks. On October 12, 2021, President Xi Jinping announced the creation of the first national parks. Therefore, it is of great practical significance to explore the management of natural resources in national parks, and it can provide reference for the future management of resources and environment. In order to summarize the pilot experience and promote the management of natural resources assets in national parks, we investigate the pilot of natural resource management system in national parks.

Progress: The results indicated that the management of natural resources in the national park pilots has made progress in the institutional setup, local legislation, and with distribution of powers and responsibilities. In terms of the organizational framework, China has built three forms of national park management, including central vertical management, central and local joint management, and local management. The provincial legislature issued five laws and regulations for national parks that inform matters such as natural resources investigation and registration, natural resources inventory, and the prohibited behavior of natural resources, which provides a legal basis for national park managers. The Nanshan, Shennongjia and Wuyishan national park services have issued a list of powers and responsibilities to clarify the division of responsibilities. However, there are still some problems with the national parks,

收稿日期: 2021-05-08; 接受日期: 2021-10-01

* 通讯作者 Author for correspondence. E-mail: likuan@nieer.ac.cn 
such as the complex mapping relationship of natural resource management system in national parks, the need for further rationalization of natural resource tenure, the need to speed up the top-level design of the parks, and more.

Suggestions: Based on our results, we propose the following management suggestions: (1) building a centralized and unified management system to uniformly perform the duties of owners of natural resources, land use regulation, ecological protection, and restoration in national parks; (2) improving the legal system for national parks; (3) clarifying the ownership relationship of natural resources; (4) implementing community population transfer in an orderly manner.

Key words: national park; natural resource management; organization framework; land ownership

党的十八届三中全会提出了健全国家自然资 源资产管理体制和建立国家公园体制两项改革任 务, 并开展了试点工作(新华社, 2013)。实践证明, 地方试点探索是推动改革的基本动力之一, 但需要 在中央和地方有效互动并形成相互支撑的前提下 才能够有效发挥作用。一般来讲, 中央设立目标和 原则, 地方采取多元化实践来检验, 并促进政策调 整完善。

自然资源和国家公园体制改革是生态文明建 设的重要内容, 也是央地互动的重要领域(秦天宝 和刘殁即, 2020)。一方面, 国家公园自然资源属于 国家战略性自然资源使用和保护基本公共服务范 畴，应当由中央行使国家公园财政事权; 另一方面, 国家公园的本质是生态保护和经济发展平衡的议 题, 具有很强的地方属性。

2021年10月12日, 习近平主席宣布设立第一批 国家公园。因此, 开展国家公园自然资源管理央地 关系探讨具有较强现实意义, 能够为资源环境领域 未来管理提供参考。

\section{1 中央政策目标和地方实践}

中央在国家公园体制试点区开展了国有自然 资源资产管理体制试点, 同时快速推进党和国家机 构改革，建立了自然资源管理体制(韩爱惠，2019)。 但在实际运行过程中, 国家层面尚未建立国家公园 等重要生态空间的自然资源管理体制, 省级层面国 家公园管理机构未能有效履行国有自然资源资产 所有者职责。因此, 根据试点经验完善自然资源管 理体制, 建立切合实际的国家公园自然资源管理体 系成为当前十分紧迫的问题(周㽎等, 2020)。

\section{1 国家公园自然资源管理政策演进}

2017年, 《建立国家公园体制总体方案》提出, “统筹考虑生态系统功能重要程度、生态系统功能 外溢效应、是否跨省级行政区和管理效率等因素,
国家公园内全民所有自然资源资产所有权由中央 政府和省级政府分级行使。其中, 部分国家公园的 全民所有自然资源资产所有权由中央政府直接行 使，其他的委托省级政府代理行使。条件成熟时， 逐步过渡到国家公园内全民所有自然资源资产所 有权由中央政府直接行使”。2019年，《关于统筹推 进自然资源资产产权制度改革的指导意见》对以上 内容再次予以明确, 并提出将国家公园全民所有自 然资源资产所有权代表行使主体登记为国务院自 然资源主管部门。2020年，《自然资源领域中央与 地方财政事权和支出责任划分改革方案》提出, “根 据建立国家公园体制试点进展情况, 将国家公园建 设与管理的具体事务, 分类确定为中央与地方财政 事权, 中央与地方分别承担相应的支出责任”。

从政策演进来看, 中央主要聚焦于确定国家公 园国有自然资源所有权主体。由于构建自然资源管 理体系是一项敏感而细致的政治和法制系统工程, 中央尚未完全明确管理体制构建、机构职责划分、 事权支出责任等内容, 需要丰富的地方实践经验和 更多的央地互动予以支撑(孙鸿赝和张小鹏, 2019)。

\section{2 国家公园自然资源管理实践}

目前我国共有 10 个国家公园体制试点(欧阳志 云等, 2021)。试点期间, 各个试点区的自然资源管 理主要围绕确立管理主体、推动相关立法、明确职 责划分三个方面开展实践。

在确定国家公园管理主体方面，我国构建了形 式多样的国家公园自然资源管理体制，大致可以归 为三类：一是由中央政府委托国家林业和草原局 (国家公园管理局)管理，具体由国家公园管理机构 行使。如东北虎豹国家公园管理局(东北虎豹国家公 园国有自然资源管理局), 二是中央政府委托省政 府管理, 具体由国家公园管理机构行使, 如三江源 国家公园管理局(三江源国有自然资源资产管理 局)。三是地方政府委托国家公园管理机构行使, 如 
神农架国家公园管理局。

在推动相关立法方面, 各省级立法机构相继出 台了《三江源国家公园条例(试行)》等 5 部国家公园 地方性法规, 主要围绕自然资源本底调查、自然资 源统一确权登记、自然资源禁止利用行为等方面作 出了规定, 为国家公园自然资源管理提供了法律依 据。由于立法时间不同和政策的发展演进, 各国家 公园地方性法规的功能分区和管控措施不尽相同。 如《云南省国家公园管理条例》将国家公园分为四 类功能分区, 而《三江源国家公园条例(试行)》将 国家公园分为三类功能分区, 实行不同的空间管制 措施。

在明确职责划分方面，南山、神农架、武夷山 等国家公园管理机构印发了权责清单。其中, 《湖 南南山国家公园管理局行政权力清单(试行)》根据 省相关部门授权, 设置了6项关于自然资源利用的 行政许可, 但无相关行政处罚规定; 《神农架国家 公园管理局权责清单》设置了自然资源利用相关行 政处罚条款, 但未设置相关行政许可; 《武夷山国 家公园管理局权责清单》设置了林木采伐行政许可 1 项，其他自然资源利用行政处罚 20 余项。

\section{2 国家公园追然资源管理存在的问题}

中央要求在条件成熟时, 逐步过渡到国家公园 内全民所有自然资源资产所有权由中央政府直接 行使, 目前国家公园自然资源管理仍在过渡阶段, 尚未完成自然资源管理由分级行使到集中统一行 使的转变, 这主要是自然资源管理体制、自然资源 权属、管理顶层设计等原因所致(李博炎等, 2021)。

\section{1 国家公园自然资源管理体制映射关系复杂}

从政策演进来看, 组建对各类国有自然资源统 一行使所有权的机构其条件尚不成熟, 也因此形成 了土地、矿产、草地、林地、水资源、野生动物等 自然资源有偿使用仍由自然资源、林草、水利、农 业农村部门来行使的“九龙治水”局面。现行自然资 源管理体制投射到国家公园等重要生态空间则显 得尤为复杂。尽管中央文件明确“国家公园管理机 构主要负责国家公园范围内自然资源资产管理和 生态保护修复的职能定位”, 但由于国家公园上位 法缺失、改革没有完全到位, 国家林业和草原局(国 家公园管理局)尚未落实国家公园范围内土地、矿
产、水资源、水生野生动物等自然资源管理权限，而 是仍由自然资源部、水利部、农业农村部等部门行 使。以三江源国家公园为例, 2017年, 组建了三江源 国有自然资源资产管理局和相应的县级管理机构, 承担三江源国家公园范围内各类全民所有自然资 源资产所有者职责，从中央到省州对应自然资源、 林草、农业农村、水利等多个部门。由于自然资源 管理是分级管理体制, 且从中央到省州均有相对应 的管理部门, 大部分国家公园管理机构未开展自然 资源相关行政许可，国家公园自然资源所有者职责 尚未得到落实。

\section{2 国家公园自然资源权属需进一步厘清}

目前, 10 个国家公园体制试点区内约有 50 万居 民，涉及大量国有土地和集体土地，自然资源权属 较为复杂, 人地矛盾突出(方言和吴静, 2017; 何思 源和苏扬, 2021; 藏振华等, 2021)。如何处理好自然 资源国家所有权和集体所有权、所有权和承包权、 承包权和经营权的关系, 是国家公园处理生态保护 和经济发展之间关系的根本所在, 也是未来国家公 园自然资源所有权由分级行使到集中统一行使的 条件之一。厘清自然资源所有权和承包权也是解决 目前国家公园范围内人兽冲突、野生动物与家畜争 夺草场、生态移民搬迁等问题的关键所在。

目前, 国家公园自然资源权属不清晰主要表现 在三个方面: 一是所有权不清晰。主要是由于历史 原因而存在自然资源产权纠纷, 如省界纠纷、集体 纠纷等问题。如三江源国家公园地处青海与西藏边 界, 草场产权存在纠纷。二是承包权有待保障。目 前生态搬迁虽有相应补偿, 但多为一次性安置费用, 无法实现农牧民家庭的长期可持续发展, 不利于国 家公园人口有序转移。如部分国家公园体制试点区, 搬迁群众已不再从事农牧业生产, 丧失了原来的生 产生活资料。由于文化水平、身体健康等因素, 部 分群众存在返贫风险。三是经营权有待保障。主要 是指土地承包到户后, 流转到合作社或生产大户进 行集约化、规模化经营, 从而获取一定的地租或分 红收入。对于这部分租赁未到期的土地, 如果强行 流转, 极易引发纠纷和矛盾。

\section{3 管理顶层设计需进一步加快}

国家公园自然资源管理在我国是新生事物, 尽 管地方在立法、明确职责划分等方面开展了探索, 
但中央在立法、权责关系、事权与支出责任等方面 的管理顶层设计需要进一步加快。一是国家公园立 法暂时空缺。目前, 《国家公园法》正在研究和起草 阶段, 与自然资源相关法律修订缺乏统筹协调, 国 家公园自然资源管理工作缺乏法律依据。尽管各省 出台了国家公园地方性法规, 但受《中华人民共和 国自然保护区条例》限制, 较难落地实施。二是国 家公园自然资源管理方式有待明确。中央要求由国 务院自然资源主管部门行使或委托相关部门、省级 政府代理行使, 在条件成熟时过渡到由中央政府统 一行使。然而在实践探索中, 大部分国家公园自然 资源所有权仍由各级政府分级行使。因此, 未来国 家公园自然资源管理继续由各级政府分级行使还 是由中央政府或地方政府集中统一行使仍有待进 一步明确。三是国家公园自然资源管理支出责任有 待明确。国家公园对于维护国家生态安全屏障具有 战略性地位, 国家公园自然资源管理应当由中央承 担支出责任。然而, 国家公园实际的资金来源较为 分散, 中央未设立专门的国家公园资金渠道, 也没 有列入中央财政一般预算。例如, 三江源国家公园 中央财政资金以藏区专项、文化旅游提升工程、三 江源生态保护和建设二期工程及退牧还草工程等 项目资金为主，资金来源分散，不具有可持续性。

\section{3 国家公园自然资源管理的建议}

目前，中央从概念上将自然保护地划分为国家 公园、自然保护区、自然公园3种类型，但在管理体 制、财政事权、自然资源保护利用、范围大小和管 控措施、人口密度等方面尚未作出明确界定, 国家 公园定位需进一步清晰。从央地关系视角来看, 其 中国家公园自然资源管理最为关键。因此, 针对国 家公园自然资源管理笔者提出如下建议。

(1)构建集中统一管理体制。中央层面, 统筹国 家公园、大江大河等重要生态空间, 由国家林业和 草原局(国家公园管理局)负责国家公园等重要生态 空间的自然资源资产管理、国土空间用途管制和和 生态保护修复职责, 衔接现有制度体系, 新增国家 公园自然资源管理若干司局和执法总队, 具体负责 国家公园重要自然资源的占有、使用、出让、收益、 行政执法等工作。地方层面, 成立国家公园管理局 分局, 为国家公园管理局派出机构, 由中央保障编
制和财政支出，负责国家公园自然资源日常管理 工作。

(2)完善国家公园法治体系。加快立法进程, 重 点推进《国家公园法》《自然保护地法》的立法工 作，同时启动《中华人民共和国自然保护区条例》 修订工作; 找准国家公园定位, 明确范围大小、功 能分区、人口密度、财权事权等量化指标, 确定国 家公园设立与退出机制, 与自然保护区、自然公园 严格区分, 为构建以国家公园为主体的自然保护地 体系提供法律支撑; 注重统筹协调, 推动自然资源 相关法律修改, 明确国家公园管理机构履行国家公 园自然资源所有者职责; 鼓励开门立法, 从全国抽 调人员组建立法小组, 充分汲取地方立法经验, 广 泛听取各方意见，增强立法的民主性和开放性。

(3)厘清自然资源权属关系。利用自然资源统一 确权登记成果, 加强自然资源统一调查, 进一步划 清国家公园全民所有和集体所有的边界以及不同 集体所有者的边界, 将国家公园全民所有自然资源 所有权主体登记为国务院自然资源主管部门。因地 制宜开展赎买、租赁和协议共管等方式, 减少国家 公园集体所有自然资源比例，逐步收回国家公园自 然资源承包权和经营权。坚持中央政府集中统一行 使国家公园自然资源所有权原则，同时充分调动地 方政府积极性, 研究制定国家公园分级行使所有权 自然资源清单, 划清全民所有、不同层级政府行使 所有权的边界。

(4)有序开展社区人口转移。与土地承包政策相 衔接, 根据实际情况, 设立30-60年过渡期。完善生 态补偿政策，对不再利用原有土地的国家公园居民， 置换同等土地或逐年补偿土地收益, 原有土地纳入 中央政府直接行使所有权的资源清单。培育特色产 业, 因地制宜发展特色农业、生态体验、民族产品 加工等产业, 提供多渠道就业机会, 促进国家公园 社区群众转产转业。充分发挥对口支援优势, 加大 异地办学力度, 提升国家公园社区居民受教育水平。

\section{ORCID}

李款 (D) https://orcid.org/0000-0001-7560-6670

\section{参考文献}

Fang Y, Wu J (2017) A research on the land ownership of national parks and man-land relationship in China. Tourism Science, 31(3), 14-23. (in Chinese with English abstract) 
[方言, 吴静 (2017) 中国国家公园的土地权属与人地关 系研究. 旅游科学, 31(3), 14-23.]

Han AH (2019) Discussion on natural resources asset management in national parks. Forest Resources Management, (1), 1-5, 37. (in Chinese with English abstract) [ 韩爱惠 (2019) 国家公园自然资源资产管理探 讨. 林业资源管理, (1), 1-5, 37.]

$\mathrm{He} \mathrm{SY}, \mathrm{Su} \mathrm{Y}$ (2021) Experience and improvement recommendations of Wuyishan National Park pilot: Difficulty and solutions in the reform of national park located in the collective forest area in South China. Biodiversity Science, 29, 321-324. (in Chinese) [何思源, 苏杨 (2021) 武夷山试点经验及改进建议: 南方集体林 区国家公园保护的困难和改革的出路. 生物多样性, 29, 321-324.]

Li BY, Zhu YP, Liu WW, Li S, Fu MD, Ren YH, Cai X, Li JS (2021) Pilot areas for national park system in China: Progress, problems and recommendations. Biodiversity Science, 29, 283-289. (in Chinese with English abstract) [李 博炎, 朱彦鹏, 刘伟玮, 李爽, 付梦娣, 任月恒, 蔡譞, 李 俊生 (2021) 中国国家公园体制试点进展、问题及对策建 议. 生物多样性, 29, 283-289.]

Ouyang ZY, Xu WH, Zang ZH (2021) Suggestions on improving the management system of national parks. Biodiversity Science, 29, 272-274. (in Chinese) [欧阳志云, 徐卫华, 蔵振华 (2021) 完善国家公园管理体制的建议. 生物多样性, 29, 272-274.]

Qin TB, Liu TT (2020) Constructing China's administrative system for national parks from the perspective of central-local relations. Dong Yue Tribune, 41(10), 162-171, 192. (in Chinese) [秦天宝, 刘粀粀 (2020) 央地关系视角
下我国国家公园管理体制之建构. 东岳论从，41(10), 162-171, 192.]

Sun HY, Zhang XP (2019) Discussion on natural resources management of national Parks. Forestry Construction, (2), 6-9. (in Chinese with English abstract) [孙鸿雁, 张小鹏 (2019) 国家公园自然资源管理的探讨. 林业建设，(2), 6-9.]

Xinhua News Agency (2013) Decision of the Central Committee of the Communist Party of China on Some Major Issues Concerning Comprehensively Deepening the Reform. (in Chinese) [新华社(2013) 中共中央关于全面深 化改革若干重大问题的决定.] https://www.fmprc.gov.cn/ ce/cemx/chn/gdxw/t1 100200.htm. (accessed on 2021-11-30)

Zang ZH, Xu WH, Ouyang ZY (2021) Exploration on the value realization of ecological products in China's National Park system pilots. Biodiversity Science, 29, 275-277. (in Chinese) [㶓振华, 徐卫华, 欧阳志云 (2021) 国家公园体 制试点区生态产品价值实现探索. 生物多样性, 29, 275-277.]

Zhou K, Wang L, Li X, Zhang D, Liu TK, Lin J, Liu P (2020) Natural resources management in US national Parks: Principles, problems, and enlightenments. Journal of Beijing Forestry University (Social Sciences), 19, 46-54. (in Chinese with English abstract) [周椹, 王丽, 李想, 张多, 刘天科, 林进, 刘鹏 (2020) 美国国家公园自然资源管 理: 原则、问题及启示. 北京林业大学学报(社会科学版), 19, 46-54.]

(责任编委: 徐卫华 责任编辑: 时意专、李会丽) 